\title{
Vanguarda em disputa e arte pop: estratégias de internacionalização da arte brasileira e argentina nos anos 1960
}

\author{
Alexandre Pedro de Medeiros ${ }^{1}$ \\ DOI 10.20396/eha.vil4.3432
}

No decorrer da década de 1960 no Brasil e na Argentina, algumas das questões que estiveram em pauta no debate da crítica, das instituições e dos artistas em torno de uma produção artística de vanguarda, como assimilação e dependência, ou hibridização e autenticidade, tiveram como cenário a consolidação da pop como genealogia canônica da arte internacional.

Inicialmente, focamos na análise da produção argentina de extração pop, de sua circulação em mostras na capital argentina e no exterior realizadas nos anos 1960, da importância da atuação do crítico de arte Jorge Romero Brest na promoção dessa produção a partir de sua posição como diretor do Centro de Artes Visuais do Instituto Torcuato Di Tella e, por fim, mas não menos importante, das possibilidades comparativas com a produção brasileira da mesma época, principalmente a partir da performance de determinados agentes ${ }^{2}$ vinculados a instituições basilares para a exibição de obras de arte e para o estímulo do debate artístico, como museus, galerias, centros de arte, universidades, jornais, revistas e a Bienal de São Paulo, sobretudo sua nona edição em 1967.

Neste sentido, por ocasião de pesquisa de campo empreendida na cidade de Buenos Aires em novembro de 2018, cabe ressaltar o caráter valioso da documentação (catálogos, folders, fotografias e artigos jornalísticos) encontrada na Fundación Espigas e na Universidad Torcuato Di Tella referente às edições de 1961 a 1968 dos Prêmios Ver y Estimar, aos Prêmios Nacionais e Internacionais do Centro de Artes Visuais do Instituto Di Tella de 1962 a 1967, referência incontestável para a promoção da arte de vanguarda na capital argentina e polo estratégico de disseminação internacional da produção artística desse país ${ }^{3}$ à mostra New art of Argentina, organizada por esse instituto em colaboração com o Walker Art Center de Minneapolis, onde ela esteve em cartaz no período de 9 de

\footnotetext{
1 Mestre e Doutorando em História da Arte no IFCH/UNICAMP. Este texto é resultado de pesquisa em andamento financiada através de Bolsa de Doutorado, processo n²017/23149-0, Fundação de Amparo à Pesquisa do Estado de São Paulo (FAPESP).

2 Pensamos, especificamente, nos posicionamentos de Jorge Romero Brest, Oscar Masotta, Enrique Oteiza, Samuel Paz, Hugo Parpagnoli, Luis Felipe Noé e Rafael Squirru em Buenos Aires, mas também em Mário Pedrosa, Frederico Morais, Jayme Maurício, Mario Schenberg, José Geraldo Vieira, Waldemar Cordeiro, Hélio Oiticica, Flávio Motta, Sérgio Ferro, Ceres Franco e Jean Boghici em São Paulo e no Rio de Janeiro.

3 Para se ter uma breve noção disso, salientamos que participaram como jurados, sempre capitaneados por Romero Brest, dos Prêmios Di Tella: 1962 - Giulio Carlo Argan e James Johnson Sweeney; 1963-Jacques Lassaigne e William Sandberg; 1964 - Clement Greenberg e Pierre Restany; 1965- Giulio Carlos Argan e Alan Bowness; 1966 - Lawrence Alloway e Otto Hahn; 1967-Alan Solomon e Eduard de Wilde.
} 
setembro a 11 de outubro de 1964 e depois seguiu itinerância a outros três museus estadunidenses; à exposição 11 artistas pop: la nueva imagen, organizada pela Philip Morris International com apoio das embaixadas dos Estados Unidos em vários países e realizada no Di Tella de 29 de outubro a 12 de novembro de 1966; e ainda às mostras coletivas e individuais realizadas em destacadas galerias portenhas, como a Bonino, a Lirolay e a Rubbers, tendo essa última abrigado uma exposição de Andy Warhol de 29 de julho a 14 de agosto de 1965.

Analisado em conjunto com outros documentos (cartas e esquemas de conferências) e com a bibliografia sobre a cena artística em Buenos Aires nos anos 1960, esse material nos possibilita compreender a rede de atualização e disseminação internacional da produção de vanguarda argentina, a qual contou com a atuação imperativa de Jorge Romero Brest, quem sempre que possível usufruía de suas conexões na Associação Internacional de Críticos de Arte, no estímulo à arte pop, que podemos relacionar aos trabalhos de Marta Minujín, Delia Cancela, Dalila Puzzovio, Charlie Squirru, Edgardo Giménez, entre outros, dessa época.

Portanto, um episódio curioso envolvendo o crítico francês Pierre Restany e sua aproximação com a Argentina e o Brasil em meados dos anos 1960 vem à tona. Restany possuía um programa vanguardista (um tanto tecnofílico) de um nouveau réalisme marcado por uma oposição tanto à abstração informal quanto à arte pop - sendo essa última, segundo ele, caracterizada por uma espécie de esteticismo asséptico -, para o qual imaginou ter encontrado adeptos latino-americanos. Ou seja, seu interesse em nossa arte nada tinha de inocente e nisso havia certo caráter expansionista de seu programa. O texto de apresentação da mostra individual de Antonio Dias na Galeria Relevo, em 1964, assinado pelo crítico francês, observava o gesto de apropriação direta do real operado pelo artista e buscava colar uma suposta qualidade de "reportagem" à produção do paraibano. ${ }^{4}$ Além disso, suas várias visitas à Buenos Aires transformaram-no no cicerone oficial da jovem arte argentina ao público europeu, que foi agraciado em 1965 com um artigo na revista italiana Domus intitulado "Buenos Aires e o novo humanismo", no qual Restany expõe toda a sua fascinação com o que ele considerava ser um dos mais importantes centros internacionais da criação artística contemporânea, comparável à Nova York.

Todavia, a pauta do francês não parece ter aterrissado no continente americano do modo como ele gostaria. Em 1962, a International Exhibition of New Realists, realizada na galeria Sidney

\footnotetext{
4 MARTINS, Sérgio Bruno. "Popau Brasil”: Pop, realismo e subdesenvolvimento em 1967. In: GOGAN, Jessica (Coord.). Flipping / Revisitando Pop: estética e política nas Américas 1967-2017. Rio de Janeiro: Instituto MESA, 2018. pp. 112-113.
} 
Janis, em Nova York, onde foram apresentados trabalhos de Warhol, Lichtenstein, Oldenburg, Arman, Yves Klein, entre outros, poderia ter sido a chance para o nouveau réalisme assumir a liderança da neovanguarda internacional, mas acabou se tornando um evento fundamental para o reconhecimento da pop promovida pelos galeristas Leo Castelli e Ileana Sonnabend. Assim, é plausível que ao fracasso de Restany nos Estados Unidos tenha seguido o deslocamento de sua batalha para um alvo alternativo. Para sua infelicidade, encontrou no Rio de Janeiro e em São Paulo um ambiente de fértil debate sobre uma vanguarda eminentemente nacional, que resultaria no seminário Propostas 66, organizado na Fundação Armando Álvares Penteado em 1966, e na mostra Nova Objetividade Brasileira, realizada no Museu de Arte Moderna do Rio de Janeiro em 1967.

Por aqui também falávamos em um novo realismo, mas o de Mario Schenberg, mais dialético em relação à produção de gerações anteriores, como a de matriz abstrato-construtiva, considerada pelo físico um estágio importante para a eliminação de formas anacrônicas na arte brasileira, menos tecnofílico e mais subdesenvolvido. Próximo a isso, ainda tínhamos Waldemar Cordeiro que, em texto de 1963 sobre a edição da Bienal de São Paulo daquele ano, possivelmente impactado pelos trabalhos do escocês Eduardo Paolozzi e dos italianos Enrico Baj e Mimmo Rotella - além do contato com a teoria da informação, especialmente com a concepção de Obra Aberta de Umberto Eco -, apresentava a nova figuração não como um retorno ao figurativo naturalista, mas como uma busca por estruturas comunicantes que levassem em conta os meios de comunicação de massa, o elemento aleatório e o papel do espectador enquanto ativador da obra de arte. ${ }^{5}$ Nesta via, no ano seguinte à sétima Bienal, Cordeiro apresentou seus primeiros trabalhos relacionadas a sua formulação de uma arte concreta semântica, apelidada de popcretos por Augusto de Campos.

Provavelmente, os comentários ácidos endereçados a Restany por Frederico Morais no artigo "Colonialismo Cultural", publicado em sua coluna no Diário de Notícias no dia 11 de outubro de 1967, sejam o ápice dessa querela. Nele, o crítico mineiro, que rotula o francês como "uma espécie de caixeiro viajante da arte internacional e particularmente da Escola de Paris" ${ }^{\prime 6}$, rebate as afirmações do francês de que as obras brasileiras estavam ainda meio trôpegas. Ademais, é nesse texto que Morais, ao evocar a vocação antropofágica da cultura brasileira, aponta que o que artistas como Rubens Gerchman, Antonio Dias e Marcello Nitsche estavam fazendo era "uma pop antropofágica, uma 'pop pau Brasil', não poparte mas popau"7. Para ele, o que Restany chama de vanguarda trôpega

\footnotetext{
5 CORDEIRO, Waldemar. VII Bienal: "nova figuração" denuncia a alienação do indivíduo. Brasil Urgente, São Paulo, n. 40, dez. 1963.

6 MORAIS, Frederico. Colonialismo Cultural. Diário de Notícias, Rio de Janeiro, 11 out. 1967. ${ }^{\text {a }}$ Seção, p. 3.

7 Ibid.
} 
é, na verdade, a consciência do subdesenvolvimento.

Retornando aos argentinos, em 1966 encontramos indícios da consagração da pop portenha. No Prêmio Di Tella desse ano, um dos jurados, o crítico inglês Lawrence Alloway, o maior porta-voz da pop naquele momento, anunciava que Buenos Aires era um dos mais pujantes centro de arte pop do mundo, onde uma jovem geração de artistas tinha chegado a uma síntese de formas e temas da pop internacional (Alloway se refere, obviamente, à produção britânica e estadunidense) com elementos intrínsecos ("folclóricos") da arte argentina, assim, criando uma variação da pop com um sotaque local, chamada de pop lunfardo por Restany:

Também Lawrence Alloway escreveu sobre nossa arte, em 1966: "Buenos Aires tem sido há alguns anos uma cidade com uma importante atividade dos artistas 'pop'e com um potencial ainda maior. É claro que com o Prêmio Di Tella 1966 agora é um dos mais vigorosos centro de 'pop-art' do mundo. Os artistas da geração mais jovem, que dominam a mostra, tem feito uma síntese de duas possibilidades estilísticas. Os elementos folclóricos, persistentes na arte argentina, foram fundidos às formas e temas internacionais da 'pop-art'. O resultado é que a exuberância da herança local tem sido assimilada em um genuinamente internacional. A arte 'pop' argentina tem uma nova claridade e poder..." ${ }^{8}$

Ainda em 1966, a revista de grande circulação Primera Plana ( ${ }^{\circ} 191,23$ a 29 de agosto de 1966) dedicou nove páginas ao grupo de artistas pop argentinos em uma matéria intitulada "Pop: ¿Una nueva manera de vivir?". Não queremos com isso sugerir que a interlocução de Romero Brest com Restany tenha arrefecido, mas é notável a opção conveniente adotada pelo argentino tendo em vista a equiparação da qualidade da produção que estimulava àquela considerada a mais avançada internacionalmente, sobretudo após Robert Rauschenberg ser premiado com o Leão de Ouro na Bienal de Veneza em 1964.

As questões apontadas acima compreendem apenas um esboço de um panorama muito mais complexo que estamos traçando sobre as estratégias de internacionalização da arte brasileira e argentina nos anos 1960 e suas afinidades (ou divergências) com a pop, panorama esse que será o teor do segundo capítulo da tese. No Brasil a maioria dos críticos, ao menos até a $9^{\text {a }}$ Bienal de São Paulo, não foi muito receptiva à pop e frequentemente rebatia associações entre ela e nossos artistas. Mário Pedrosa foi um dos que entrou nessa querela. Os fatores que levaram a essa diferença são múltiplos e ainda não foram dimensionados pela historiografia, porém acreditamos que a maturidade alcançada pelo debate, iniciado na década anterior, em torno de uma vanguarda na-

8 ROMERO BREST, Jorge. El arte en la Argentina: últimas décadas. Buenos Aires: Paidós, 1969. pp. 109-110. 
cional e a interlocução de artistas e críticos brasileiros com outras vertentes neofigurativas dos anos 1960, como a nouvelle figuration que, aliás, marcou presença no Rio de Janeiro em duas marcantes ocasiões, primeiro em 1964 na mostra Nova Figuração da Escola de Paris, realizada na Galeria Relevo, e um ano depois na lendária Opinião 65, organizada por Ceres Franco e Jean Boghici, proprietários da Relevo, atuaram fortemente nessa direção. Vale também recordar a exposição na Galeria Bonino, em 1963, que apresentou obras dos argentinos da otra figuración Ernesto Deira, Rómulo Macció, Luis Felipe Noé e Jorge de La Vega aos cariocas e impressionou Gerchman, Dias e Anna Maria Maiolino.

Eventualmente, essa discussão terminológica (nova figuração, novo realismo, pop) pode parecer inerte, mas, na realidade, ela nos remete a posições estratégicas definidas de agentes específicos que atuam no circuito artístico. No exercício comparativo, tanto entre as exposições International Pop e The World Goes Pop quanto entre as produções brasileira e argentina, que estamos realizando essa discussão é fundamental. Outrossim, isso nos possibilita compreender certos vícios da historiografia, alguns dele cometidos até inconscientemente, que precisam ser elucidados, como o da defesa de uma nova figuração brasileira, e não de um novo realismo ou de uma pop, ficando esse último mais restrito ao universo das galerias, o que é bastante sintomático.

A situação argentina nos anos 1960 parece mais bem-resolvida do que a nossa, pois toda a narrativa construída em torno do Di Tella dá conta de explicar o sucesso da pop argentina. Entretanto, apesar do prestígio desse instituto, o circuito não se restringia apenas a Buenos Aires, principalmente quando a Bienal Interamericana de Córdoba disputava, apostando mais na consagração de uma produção já reconhecida do que no incentivo a uma atitude de vanguarda, com a capital o posto de vetor de internacionalização. Ao mesmo tempo, não é difícil observar que muito do que era produzido sob os auspícios de Romero Brest, como os colchões de Marta Minujín ou os gessos de Dalila Puzzovio, estava muito mais próximo, contrariando as intenções do crítico, do nouveau réalisme do que da pop estadunidense. ${ }^{9}$ Ou seja, esses movimentos e seus desdobramentos são mais embaralhados do que, à primeira vista, poderíamos cogitar.

9 GIUNTA, Andrea. Vanguardia, internacionalismo y política: arte argentino en los años sesenta. Buenos Aires: Paidós, 2001. p. 274. 


\section{Referências Bibliográficas}

CORDEIRO, Waldemar. VII Bienal: "nova figuração" denuncia a alienação do indivíduo. Brasil Urgente, São Paulo, n. 40, dez. 1963.

GIUNTA, Andrea. Vanguardia, internacionalismo y política: arte argentino en los años sesenta. Buenos Aires: Paidós, 2001.

GOGAN, Jessica (Coord.). Flipping / Revisitando Pop: estética e política nas Américas 1967-2017. Rio de Janeiro: Instituto MESA, 2018.

MORAIS, Frederico. Colonialismo Cultural. Diário de Notícias, Rio de Janeiro, 11 out. 1967. $2^{\text {a }}$ Seção, p. 3.

ROMERO BREST, Jorge. El arte en la Argentina: últimas décadas. Buenos Aires: Paidós, 1969. 